\title{
Controlling Vibration Speed in Tunnel Excavation Using Fine Blasting Method under Complex Environmental Conditions
}

\author{
Yingcai Zhang $\left(\mathbb{D},{ }^{1}\right.$ Jiyun Zhang $\mathbb{D}{ }^{1},{ }^{1}$ Shuren Wang $\mathbb{D}^{1,2}$ and Yubo Chen ${ }^{1}{ }^{1}$ \\ ${ }^{1}$ International Joint Research Laboratory of Henan Province for Underground Space Development and Disaster Prevention, \\ Henan Polytechnic University, Jiaozuo 454003, China \\ ${ }^{2}$ School of Minerals and Energy Resources Engineering, University of New South Wales, Sydney, NSW 2052, Australia
}

Correspondence should be addressed to Shuren Wang; w_sr88@163.com

Received 6 July 2021; Accepted 16 September 2021; Published 30 September 2021

Academic Editor: Jiaxi Zhou

Copyright (c) 2021 Yingcai Zhang et al. This is an open access article distributed under the Creative Commons Attribution License, which permits unrestricted use, distribution, and reproduction in any medium, provided the original work is properly cited.

It is very important to reduce the impact of blasting vibration on the surrounding structures during the tunnel drilling-blasting excavation. Taking the diversion tunnel of the urban water supply project in Zhumadian, Henan Province, China, as an example, the segmentation linear function between the drilling rig and borehole depth was established by fining blasting design. The test of the blasting number and particle vibration velocity was designed. The propagation and attenuation characteristics of blast vibration velocity in the surrounding rocks of the tunnel were analyzed by using theoretical calculation and field monitoring methods. Results show that the fine blasting design can realize the superposition of negative phase of shock waveform to reduce the vibration speed. With the increase of the blasting number, the attenuation of the particle vibration velocity shows a negative exponential function, and the dimensionless vibration velocity loss increases in a power function. The greater the loss, the greater the energy loss during the shock wave propagation process, which is more conducive to ensuring the stability of the protected buildings. The research results can provide the reference for similar engineering practices.

\section{Introduction}

At present, the blasting technology still occupies an important position in the construction of various underground engineering and the demolition of various buildings. Particularly in sections where the tunnel length is short and the surrounding rock is relatively broken, the blasting technology can speed up construction, increase production efficiency, and produce significant economic and social benefits [1-3]. However, the secondary disasters caused by the blasting operations, especially the effects of blasting vibration, will bring certain problems to the local environment and residents' lives. The particle vibration effect caused by the explosive explosion is very complicated. Various factors such as construction geological conditions, explosion area topography, and propagation medium will affect the vibration and attenuation characteristics. The amplitude, period, and frequency of different shock waves in time and space are also changing in real time. Generally, the strength of the blast vibration effect is generally evaluated by the particle vibration velocity [4]. Therefore, the research on the control of blasting vibration is a hot topic of current research.

The high temperature-pressure wave generated by the explosive in the borehole will be converted into a shock wave in a short time to propagate in the medium, and the energy carried by the shock wave will make the surrounding rock shear and tensile stresses, which will further deteriorate the mechanical properties of rock mass in cyclic blasting. To weaken the particle vibration caused by blasting, Kim and Song used abrasive water jet cutting blasting to control particle vibration and found a significant reduction in vibration compared to that caused by the conventional drilling method [5]. Liu et al. concluded that the borehole amount had a significant effect on the optimal differential time and the corresponding maximum synthetic vibration speed, and the effect of vibration reduction could be achieved by designing a reasonable delay time to make the waveform 
anisotropic phase dissipation [6]. Yang et al. compared the unloading damage mechanism and rockburst events of the surrounding rock in shield machine and borehole-blasting method, and they found that the scale and frequency of rockburst events generated by shield machine were higher than those of the borehole-blasting method in the stress adjustment process of large burial depth tunnel excavation [7]. To improve the excavation efficiency, Ma et al. obtained the critical distance of the borehole restraint by field test and they proposed a new charging structure without detonating cord and achieved a good smooth blasting effect [8]. Chai et al. studied the effect of the arrangement of cut holes on the control blasting effect and they found that the layout of four empty holes could improve the utilization rate of explosive better than the two, indicating that reasonable reserved compensation space could improve the blasting effect and tunneling efficiency [9]. Duan et al. investigated the influence of blasting excavation on existing tunnels under small spacing [10]. Wang et al. studied the rule of buffer layer on vibration velocity and propagation energy attenuation by constructing a specific shape of loose body, and they found that a reasonable arrangement of buffer layer in oriented blasting could greatly reduce touchdown vibration [11].

For deeply buried underground spaces, Yang et al. studied the effect of differential blasting on the evolution of the rock stress field by establishing a two-dimensional circular excavation model, and they found that two blasts before and after the stress adjustment process would cause a shift in the direction of the maximum and minimum principal stress [12]. Chen et al. believed that the blasting damage zone in the surrounding rock was caused by the redistribution of stress in the surrounding rock after excavation, and the dynamic damage effect caused by the instantaneous unloading of stress after blasting was more significant under high ground stress [13]. Fan et al. compared the influences of quasistatic and transient unloading on the range of damage in the surrounding rock by theoretical calculations and numerical simulations, and they found that the transient unloading had a larger impact range [14]. Taking the practical engineering as an example, Xie et al. conducted a theoretical analysis of strain energy adjustment during blasting and mechanical excavation, and they found that the frequency of secondary disasters caused by blasting excavation was much higher than that of mechanical excavation [15]. While for the shallow buried underground engineering, Xia et al. investigated the influence of blasting vibration on water supply pipelines and found that reducing the water pressure of pipeline could reduce the injury caused by blasting vibration [16]. Jiang et al. optimized the Sadovsky formula by regression analysis of field data to establish a three-dimensional model of gas pipeline under the action of blast vibration and to verify the feasibility [17]. Chen et al. found that the peak vibration velocity of the excavated section was greater than that of the unexcavated section when the tunnel was buried at a shallow depth, and this phenomenon gradually disappeared as the burial depth increased [18]. Shi et al. found that the phenomenon of "hollow effect" existed in the process of excavation blasting, and the intensity of this phenomenon was proportional to the distance from the excavation face [19]. Liu and Chen established a prediction method for surface vibration waveform caused by the cutting hole blasting in tunnel construction, and they verified the correctness of the prediction method using the field measurement data [20].

In summary, there are few reports on the whole process from equipment selection to blasting effect tracking in tunnel blasting excavation. According to local environmental conditions, the fine blasting design is significant to improve construction efficiency and reduce the impact of blasting shock waves on the environment. This study intends to carry out a fine blasting design from the aspects of equipment selection, the determination of borehole depth, and the design of borehole parameters and obtain the function relationship between the drilling equipment and borehole depth to ensure the construction efficiency. Based on theoretical calculations and field observed values, the monitoring analysis of vibration velocity decay characteristics was conducted, the connection between the particle vibration velocity and the cyclic blasting times was proposed, and the rationality of this fine blasting design was verified.

\section{Materials and Methods}

2.1. Engineering Background. As shown in Figure 1, taking the new diversion tunnel of the urban water supply project in the eastern part of Zhumadian, Henan province, China, as an example, the diversion tunnel was located $76 \mathrm{~m}$ west of the existing diversion tunnel, these two tunnels were parallel to each other, their excavation diameter was $3200 \mathrm{~mm}$, and the design water intake capacity was $2.5 \mathrm{~m}^{3} / \mathrm{s}$. There were civil buildings at $40 \mathrm{~m}$ on the north and $60 \mathrm{~m}$ on the west, the positive operation gate was located $90 \mathrm{~m}$ on its east, the reservoir was on the south, and the construction environment was complicated.

Influenced by the geological environment and the project, the engineering was excavated by using the drillingblasting method. The shaft was constructed first and then the diversion tunnel, and the depth of the shaft was $38.45 \mathrm{~m}$. The blasting vibration effect was more obvious at the same horizontal position with larger elevation, which had an amplification on the particle vibration velocity. Therefore, the fine blasting should be conducted during the construction of the new diversion tunnel to ensure the existing diversion tunnel and the surrounding buildings are not being affected.

The hydrogeology of the construction location directly affects the selection of equipment, the calculation of borehole depth, and the determination of explosive consumption, which is an integral part of the fine blasting. The region was located in the combination of the southern edge of the North China Platform and the Qinling fold belt, with a strong geological structure, influenced by tectonic stress and more folds and joints developed around. The construction site was mainly strongly weathered rock with different thickness of 1.4-2.0 m, conglomerate of $0.5-10.0 \mathrm{~m}$, slightly weathered rock of $0.6-21.6 \mathrm{~m}$, quartzite of $9.0-52.5 \mathrm{~m}$, and gneiss of $0-52 \mathrm{~m}$, respectively. 


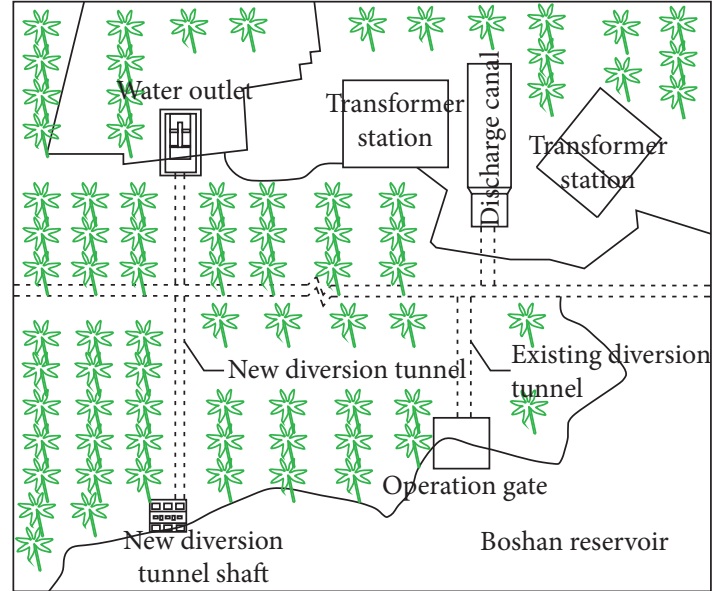

(a)

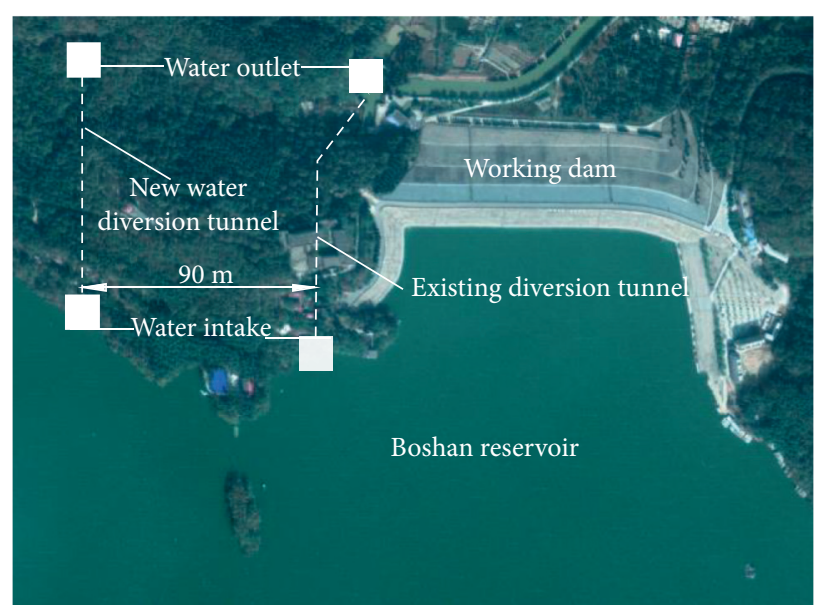

(b)

FIgURE 1: Environmental conditions around water conveying tunnels. (a) Schematic plan. (b) Real map.

2.2. Fine Blasting Evaluation Equipment. To evaluate the accuracy of the fine blasting design, the vibration velocity was tested at the same measurement points at each blasting to determine the attenuation of the shock wave. The measuring instrument of blasting vibration was Blast-UM, with the resolution of 24 -bit $A / D$, sampling rate of $10 \mathrm{ksps}$, frequency response range $5-300 \mathrm{~Hz}$, measurement range $0.01-350 \mathrm{~mm} / \mathrm{s}$, and working temperature from -10 to $70^{\circ} \mathrm{C}$, which can directly measure the vibration signal in three directions simultaneously, and 2G of memory can meet the needs of multistage charge and long delay in tunnel blasting. The detailed operation method is shown in Figure 2. The equipment has the advantages of high precision, large memory, good compatibility, and simple operation, which is widely used in vibration testing caused by human activities.

\subsection{Fine Blasting Design}

2.3.1. Determination of Borehole Diameter and Depth. The size of the borehole diameter directly affects the borehole speed, the number of boreholes in the working face, unit explosive consumption, the size of rock block after blasting, and the flatness of the roadway profile. The increase of borehole diameter is conducive to improve the stability of the explosion and increase the explosion speed. While the diameter is too large, the borehole speed decreases, which will reduce the average distribution factor of explosive in the construction area and lead to poor quality of rock crushing under the premise of unchanged construction section, borehole depth, and loading coefficient. The LGU75A mobile air compressor was selected to provide power in this study and the YT18 drilling rig with a $40 \mathrm{~mm}$ diameter was used for drilling.

The most suitable borehole depth should be determined according to the mechanical equipment, technology process, rock geology, and organizational management capabilities. To bring out the optimal capacity, improve the efficiency of each process, and reduce the number of man-hours of an effective unit length of roadway, determining the borehole depth according to local conditions was an important part of the fine blasting. Ignoring the influence of human factors, the drilling test with the selected equipment was carried out and statistical analysis of borehole speed, time-consuming, and hole depth was performed. As seen from Figure 3, the borehole depth is not linearly related to the time-consuming per unit length and the borehole speed. The performance is that the time-consuming per unit length varies slowly and then increases rapidly with increasing borehole depth, and there is a threshold value. The specific performance is that the designed borehole depth increment is $0.2 \mathrm{~m}$, and the node appears when the increment reaches $0.4 \mathrm{~m}$. When the borehole depth is $2.0 \mathrm{~m}$, the timeconsuming per unit length is $3.06 \mathrm{~min}$. When the borehole depth is $2.4 \mathrm{~m}$, the time-consuming per unit length is $3.15 \mathrm{~min}$. Under the same conditions, the time-consuming per unit length is $4.10 \mathrm{~min}$ when the hole depth is $2.8 \mathrm{~m}$, so the selected equipment will have the highest construction efficiency at a borehole depth of about $2.4 \mathrm{~m}$ in the study.

As seen from Figure 4, the time-consuming per unit length keeps increasing with increasing of the borehole depth. The piecewise function can be used to describe the whole process, which can be expressed by the linear equation $y=0.225 x+2.668$ with a correlation coefficient of 0.832 when the borehole depth is less than $2.4 \mathrm{~m}$, while this can be expressed by the linear relationship of $y=2.375 x-1.612$ with a correlation coefficient of 0.996 when the borehole depth is greater than $2.4 \mathrm{~m}$. The turning point of timeconsuming per unit length is at about $2.4 \mathrm{~m}$ borehole depth. Although the two functions are linear equations, the slope of the linear equation is about 10.6 times of the former when the borehole depth is greater than $2.4 \mathrm{~m}$, which means that the time and financial resources of drilling unit length borehole increase significantly when the borehole depth is greater than $2.4 \mathrm{~m}$, and the threshold value of the designed borehole depth should be about $2.4 \mathrm{~m}$, which is the most economical and reasonable.

2.3.2. Design of Borehole Parameters. The number of boreholes is related to several factors such as excavation section, rock characteristics, borehole diameter, borehole 


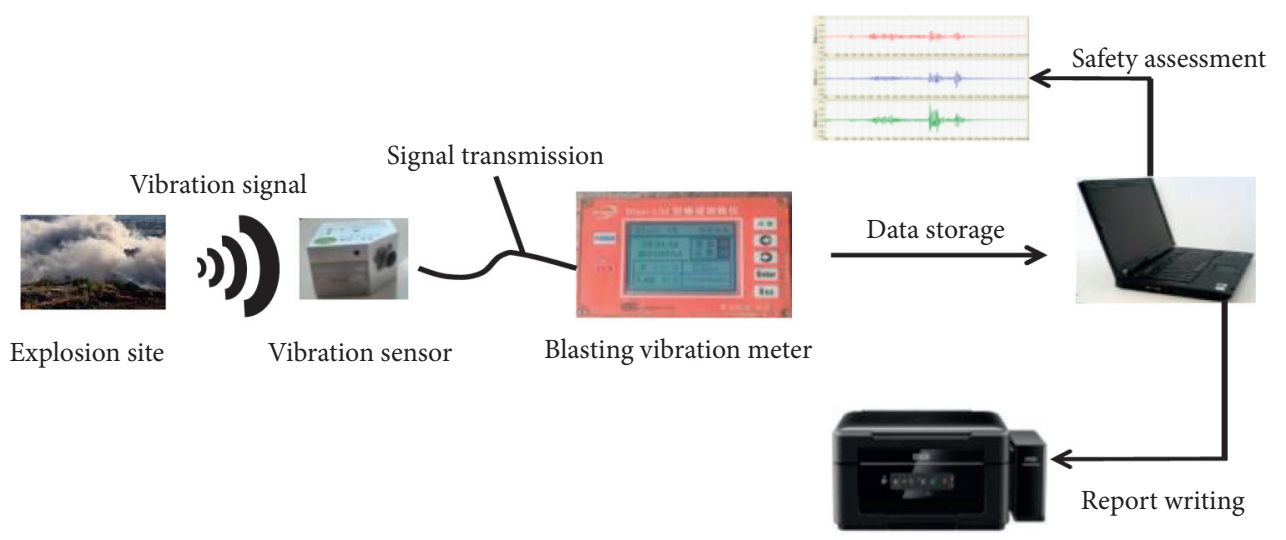

FIgURE 2: Fine blasting evaluation equipment.

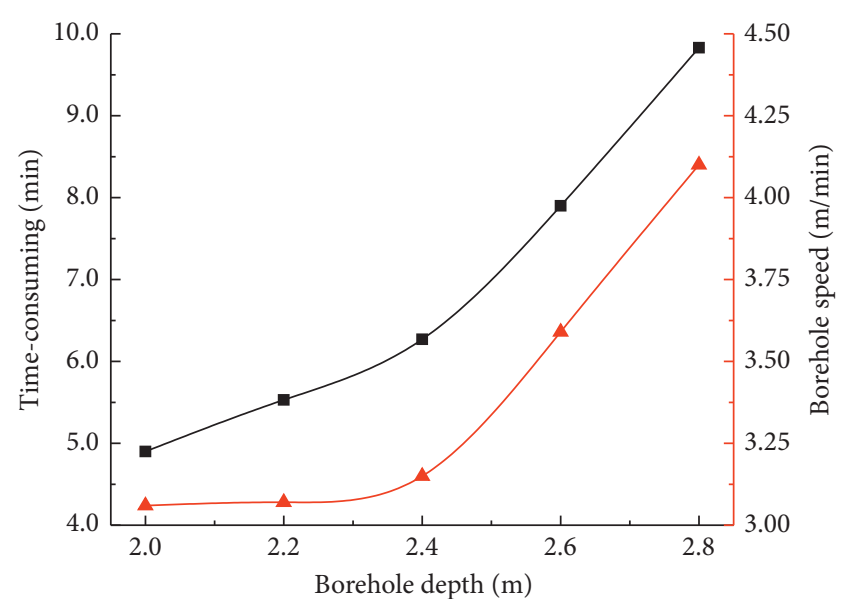

Figure 3: Relationship among the borehole depth, time-consuming, and borehole speed.

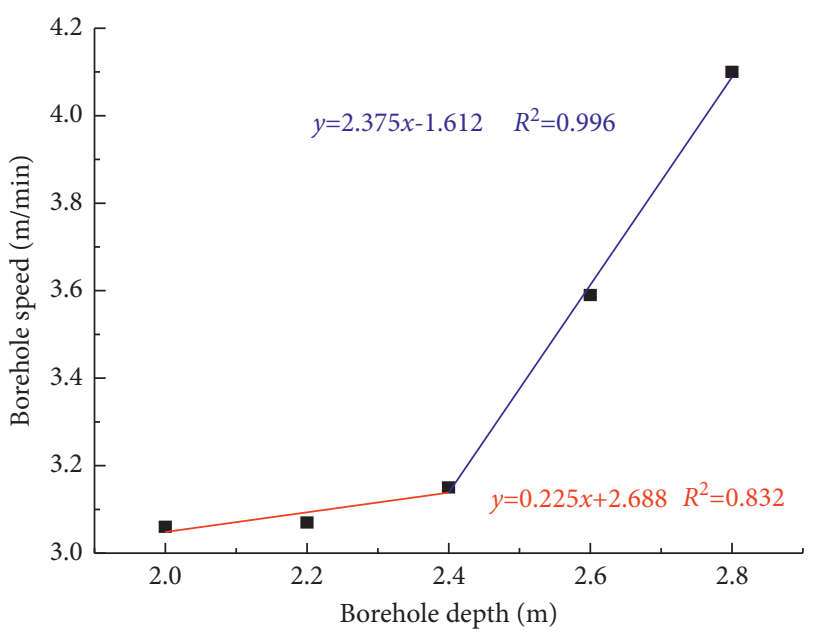

Figure 4: Relationship between the borehole depth and borehole speed.

depth, and explosive performance. Under the premise of ensuring a good blasting effect, the number of boreholes should be reduced as much as possible. The number of boreholes can be calculated as follows:

$$
N=3.3 \sqrt[3]{f s^{2}}
$$

where $N$ is the number of boreholes, $f$ is the firmness coefficient of rock, and $s$ represents the cross-sectional area of the excavation section, $\mathrm{m}^{2}$.

The borehole arrangement is a combination of theoretical calculations and construction experience, the cutting holes and periphery holes are first arranged, and then the auxiliary holes are evenly distributed in the blasted rock. The layout plan and section of the boreholes are shown in Figures 5(a) and 5(b), respectively. The spacing of cutting holes was $500 \mathrm{~mm}$, which were arranged in a wedge shape, inclined inward at an angle of $75^{\circ}$, increased the depth by $150-200 \mathrm{~mm}$, and added the charge mass by $15-20 \%$ compared with other boreholes, and the middle cutting hole was not charged. The auxiliary holes were evenly arranged in the excavation section, and the hole spacing was $640-650 \mathrm{~mm}$. To reduce the disturbance to the surrounding rock, reduce the cost of later support, and improve the construction efficiency, the periphery holes were arranged at $100 \mathrm{~mm}$ from the edge of the profile, with a hole spacing of $470 \mathrm{~mm}$, and its arrangement and charging structure were carried out according to the standard of smooth blasting.

According to experience, the charge of a single borehole is generally calculated as equation (2):

$$
Q=\eta L r
$$

where $\eta$ is the charge factor of the borehole. $L$ is the depth of the borehole, m. $r$ represents the charge weight of unit length, $\mathrm{kg} / \mathrm{m}$.

Since the geological condition of different locations varies greatly, the choice of unit explosive consumption is crucial, which not only is related to the degree of rock fragmentation and scattering distance but also has an important impact on the utilization rate of the borehole, the damage degree of surrounding rock, the quality of contouring, and later support methods [21]. Therefore, on the basis of the comprehensive analysis of explosive performance, rock characteristics, charge diameter, borehole diameter, and borehole depth and the drilling and blasting test in advance, the unit explosive consumption was determined $2.0 \mathrm{~kg} / \mathrm{m}^{3}$, and the specific value could be adjusted 


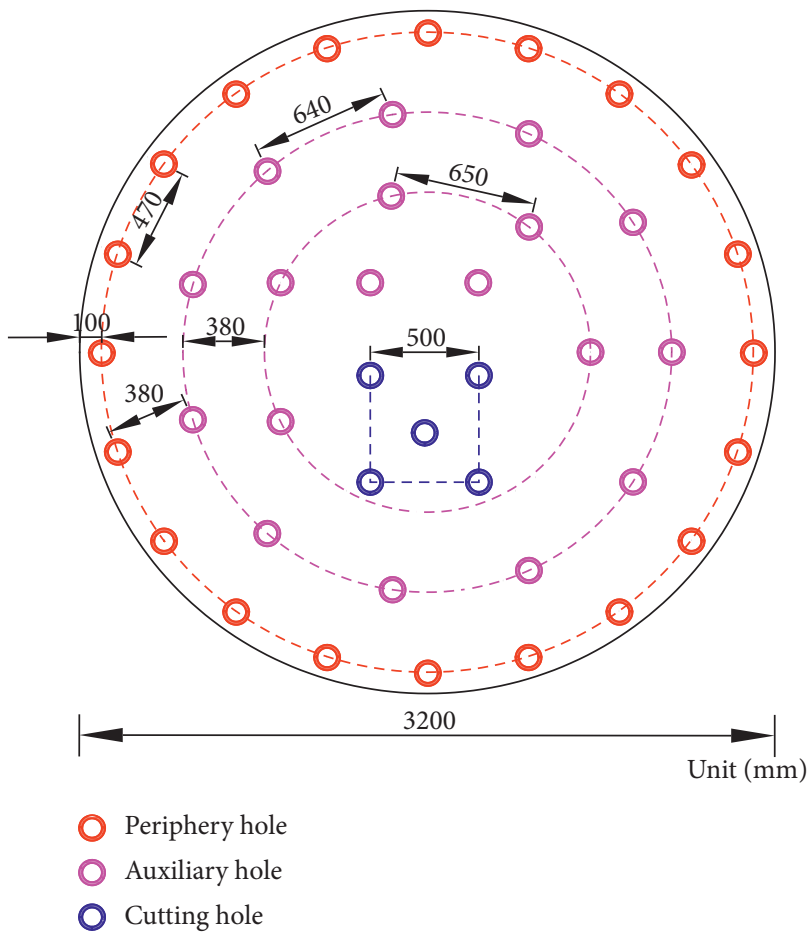

(a)

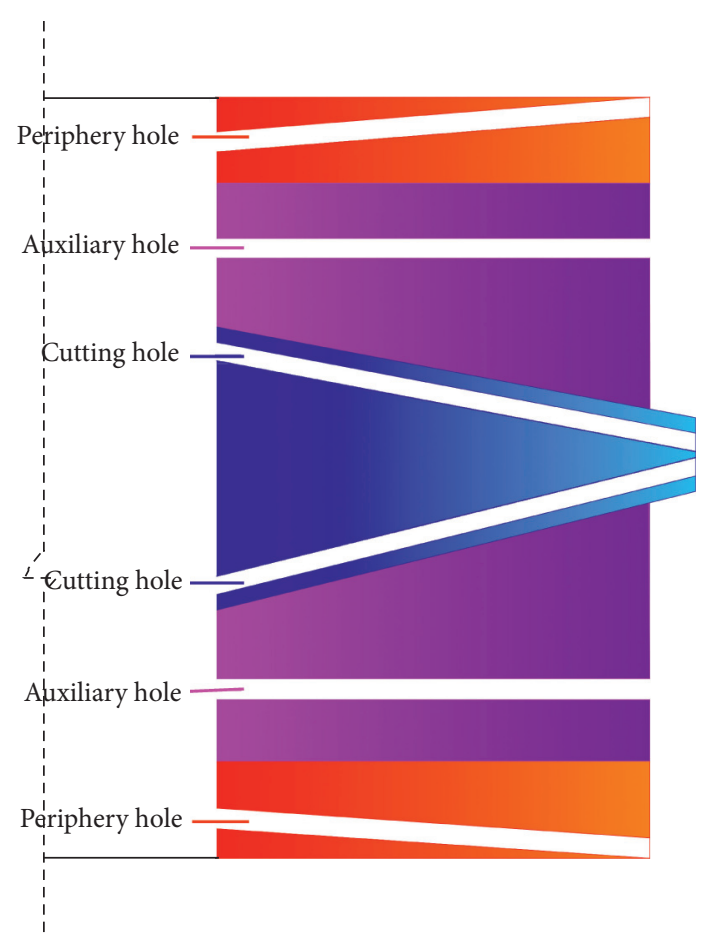

(b)

FIgURE 5: Borehole arrangement diagram. (a) Planar graph. (b) Sectional drawing.

appropriately according to the blasting effect during the construction. To ensure the blasting effect, the loading coefficients of the cutting hole, auxiliary hole, and peripheral hole were $0.6,0.5$, and 0.4 , respectively. The charge weight of unit length was taken as $1.0 \mathrm{~kg} / \mathrm{m}$. As seen from Figures 5 and 6 , the number of cutting holes, auxiliary holes, and peripheral holes were 5,18 , and 20 , respectively. The depth of the cutting hole was $2.7 \mathrm{~m}$, which was deeper than that of the auxiliary hole and peripheral hole $0.2 \mathrm{~m}$. The single-hole charge of the cutting holes, auxiliary holes, and peripheral holes was $1.6,1.2$, and $1.0 \mathrm{~kg}$, with the single section charge of $6.4,21.6$, and $20 \mathrm{~kg}$, respectively. Therefore, the total charge was $48 \mathrm{~kg}$ per cycle and the maximum priming charge of a single section was $21.6 \mathrm{~kg}$ (Figure 6).

\subsubsection{Design of Charge Structure and Detonation Network.} Charge structure has a significant impact on the blasting effect, different charge structure can affect the explosive power, the utilization rate of the released energy, the time of action of the detonation wave, and the surrounding rock. To a certain extent, through the interaction of the shock wave and the surrounding rock joints, the superposition of different shock waves without attenuation of energy can reduce the waveform peaks and troughs, extend the time for the shock wave to reach the particle, achieve the effect of reducing blast vibration, and improve the stability of surrounding rock.

In this study, the axial and radial bidirectional uncoupling charge structure was adopted, the radial uncoupling coefficient was 1.25 , and the axial uncoupling coefficients were $1.31,1.58$, and 1.71 , respectively. The radial uncoupling can be called natural uncoupling, while the axial uncoupling belongs to artificial uncoupling. Under the premise of determining the amount of charge in a single hole and ensuring the minimal resistance line is not being affected, the axial uncoupling charge can increase the height of charge, and the explosives can be more evenly distributed in the blasting area and weaken the peak pressure of shock wave, which can achieve the purpose of reducing blasting vibration, large lump rate, and blasting shock wave disturbance to the surrounding rock. In addition, it was worth explaining in this study that the boreholes were all of segmented charge structure. After determining the charge of a single borehole, borehole depth, and filling length, the charge of a single borehole calculated in advance was arranged in three equal parts in the boreholes, and one detonator was placed in each concentrated cartridge so that the explosives were evenly distributed in the blasting area and the phenomenon of antiexplosion was eliminated.

The choice of reasonable delay time and charge structure is conducive to weakening the vibration caused by shock waves and reducing the disturbance to surrounding rock. In this study, three segments of second delay detonators were selected, and the fine blasting was realized by means of outhole propagation and in-blasthole delay. Meanwhile, axial uncoupling was realized by air-spaced charge. Specifically, a certain distance of air was reserved between the bottom of the hole and the first explosive cartridge, the interval distance was determined by the charge of a single borehole and the filling length, and the position of the first explosive cartridge was determined by the distance from its end to the 


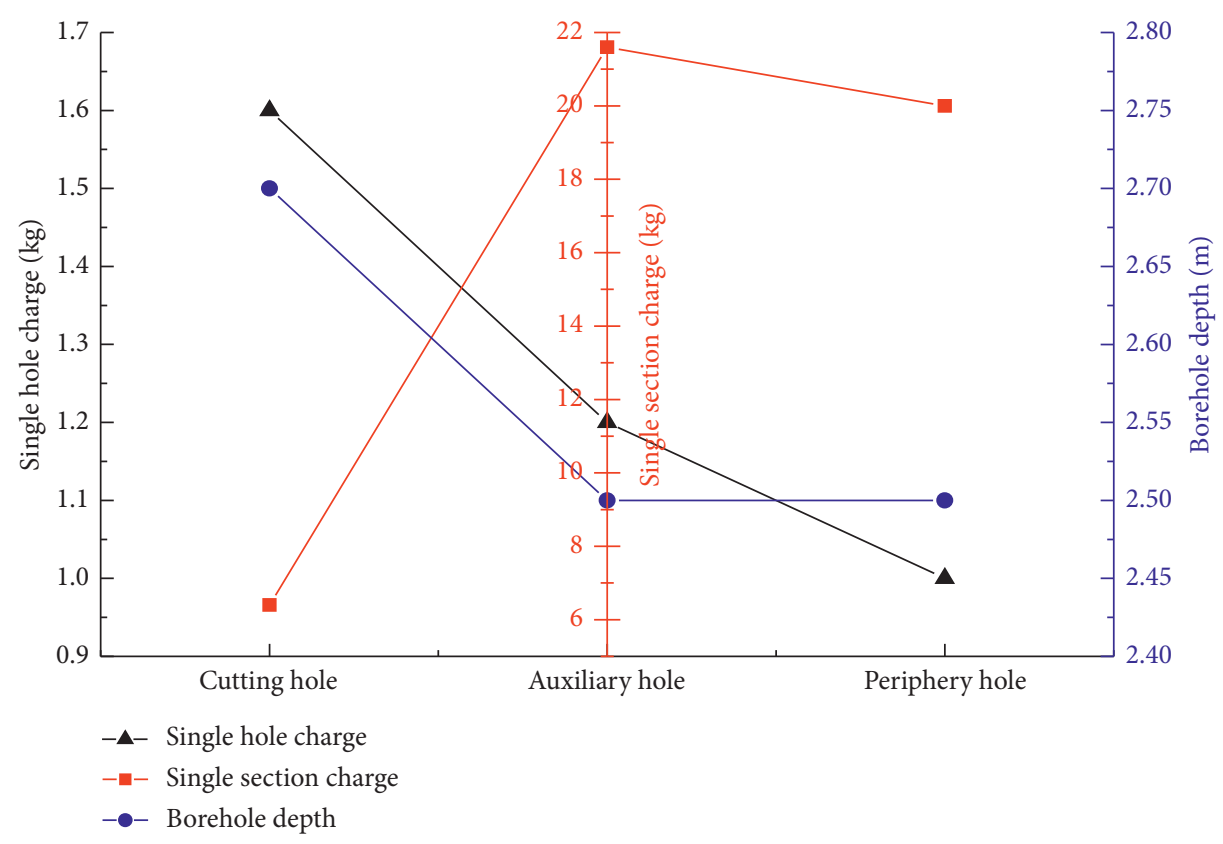

FIGURE 6: Statistics of borehole parameters' design.

orifice. The purpose of increasing the charge height and making the explosives uniformly distributed in the blasting area was realized.

\section{Results' Analysis and Discussion}

3.1. Attenuation Analysis of Vibration Velocity. The operating floodgate with the highest accuracy to be protected at $90 \mathrm{~m}$ east of the blasting site was selected as the vibration monitoring point. The particle vibration velocity can be calculated using equation (3) of Sadovsky to quantitatively determine the reasonable degree of the fine blasting design [22].

$$
\begin{aligned}
V & =K\left(\frac{\sqrt[3]{Q}}{R}\right)^{\alpha} \\
& =K \delta^{\alpha} \\
\delta & =\frac{\sqrt[3]{Q}}{R}
\end{aligned}
$$

where $V$ denotes the particle vibration velocity, $\mathrm{mm} / \mathrm{s}$. $R$ represents the distance between the protected object and blasting point, $m$. $Q$ represents the maximum charge of a single section, $\mathrm{kg}$. $K$ denotes the coefficient and $\alpha$ is the attenuation index. $\delta=\sqrt[3]{\mathrm{Q}} / R$ is the proportional dosage between the maximum single segment dosage and the effective distance [23].

There are two ways to obtain $K$ and $\alpha$ values. One is selected from the range of empirical values summarized based on the geological topography of the blast area. The other is obtained by the actual monitored particle velocity, the corresponding maximum charge of a single section, and the effective distance between the explosion sources and monitoring point, and the final solution is performed using the least squares method. The specific calculation process is as follows.

Taking the logarithm of both sides of equation (4), then

$$
\ln V=\ln K+\alpha \ln \delta
$$

Assuming that $y=\ln V, m=\alpha, x=\ln \delta$, and $n=\ln K$ and also combining the least squares principle and the extreme value theorem of the function of two variables, then equation (6) can be obtained:

$$
\left\{\begin{array}{l}
\left(\sum_{i=1}^{h} x_{i}^{2}\right) m+\left(\sum_{i=1}^{h} x_{i}\right) n=\sum_{i=1}^{h} x_{i} y_{i}, \\
\left(\sum_{i=1}^{h} x_{i}\right) m+h n=\sum_{i=1}^{h} y_{i} .
\end{array}\right.
$$

The solutions of $m$ and $n$ can be obtained from the equation (6). Continuing with the variable substitution, then equation (7) can be obtained:

$$
\left\{\begin{array}{l}
K=\ln ^{-1}\left[\frac{1}{n}\left(\sum_{i=1}^{h} y_{i}-\alpha \sum_{i=1}^{h} x_{i}\right)\right] \\
\alpha=h \sum_{i=1}^{h} x_{i} y_{i}-\frac{\sum_{i=1}^{h} x_{i} \sum_{i=1}^{h} y_{i}}{h\left(\sum_{i=1}^{h} x_{i}^{2}\right)-\left(\sum_{i=1}^{h} x_{i}\right)^{2}} .
\end{array}\right.
$$

From the above analysis, the theoretical maximum vibration velocity is $13.59 \mathrm{~mm} / \mathrm{s}$ and the minimum value vibration velocity is $2.87 \mathrm{~mm} / \mathrm{s}$. It can be seen from equation (3), under the premise of determining the distance and shock wave propagation medium, that the size of particle vibration velocity is only related to the charge mass. As seen from Figure 7, the maximum vibration velocity of the same 


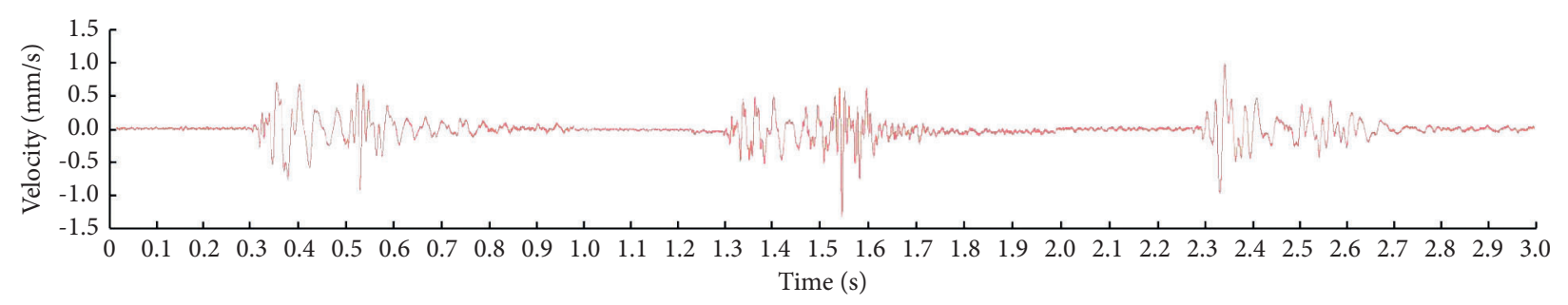

(a)

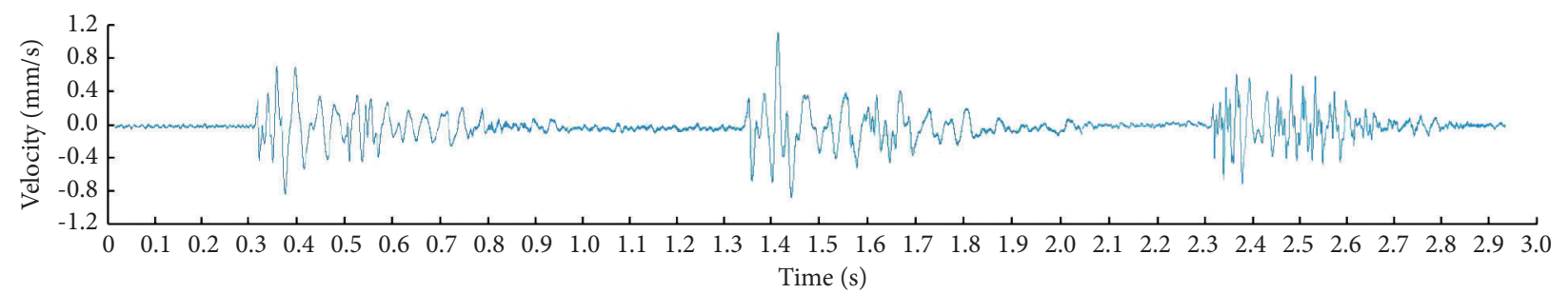

(b)

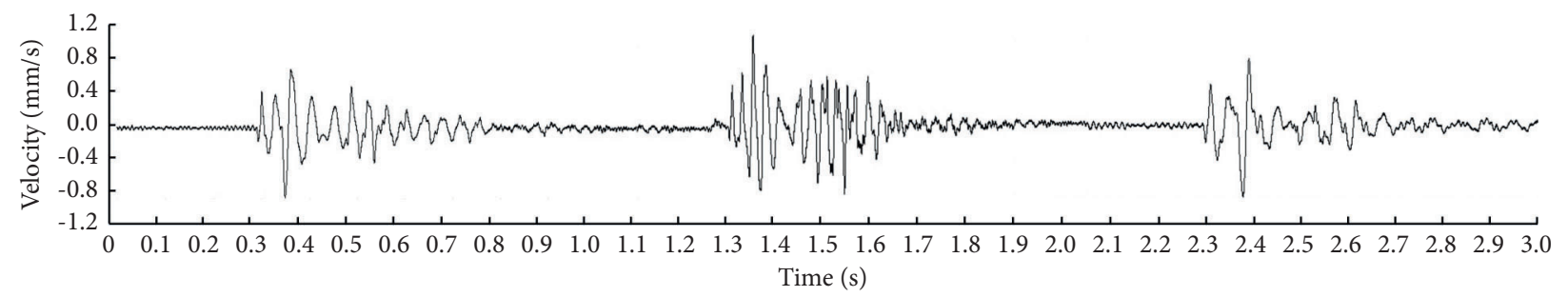

(c)

Figure 7: Vibration velocity of the same particle under different blasting. (a) First cycle blasting. (b) Second cycle blasting. (c) Third cycle blasting.

particle in three blasts was $1.33,1.13$, and $1.09 \mathrm{~mm} / \mathrm{s}$, respectively. To improve the safety factor, the theoretical minimum particle vibration velocity was compared with the measured value, the particle vibration velocity in three cyclic blasts showed a decreasing trend, and the decrease values were 0.20 and $0.05 \mathrm{~mm} / \mathrm{s}$, with a decrease of $14.84 \%$ and $4.03 \%$, respectively. The decrease of the vibration speed reflects the degree of damage caused by the last blasting to the propagation medium to some extent, and the damage to the rock mass shows an exponential function with the accumulation of the cyclic blasting numbers.

Generally, due to the borehole arrangement, single section detonation charge, and delay time, different blast vibration waveform should be large fluctuations. The fluctuation of the waveform generated by the three delay time points of each blast was not proportional to the size of the charge value, and the overall state of the waveform was relatively smooth. The reason for this phenomenon is the superimposed effect of the vibration waveform caused by the difference of the different delay time of the borehole design; meanwhile, the original and secondary damage to the rock mass between the explosion source and particle has an attenuating effect on the propagation of vibrations. As shown in Figure 7, the superposition is the negative phase superposition of waveform, and the mutual superposition of waveform reduces the propagation of shock wave energy to achieve the purpose of controlling the vibration velocity.
3.2. Effect of Cyclic Blasting on Particle Vibration Velocity. In the local blasting area, assuming that the properties of surrounding rock mass change little after the first blasting, the number of blasting is treated as a variable under the same blast design scheme. The relationship between the particle vibration velocity and blasting times shows a negative exponential function, which can be expressed by equation (8):

$$
v=a e^{-b n}+c,
$$

where $v$ denotes the particle vibration velocity, $\mathrm{mm} / \mathrm{s}, n$ denotes the number of blasting cycles, and $a, b$, and $c$ are regression coefficients.

As seen from Figure 8, the velocity decreases as a negative exponential function with the increase of the number of blasts. The absolute value of the slope of the vibration velocity decay curve between the first and second blasting is $1.97 \times 10^{-2}$, the absolute value of the slope of the vibration velocity attenuation curve between the second and third blast is $4.57 \times 10^{-3}$, and the former is 4.31 times of the latter.

Each blasting operation will produce different damage to rock mass, the slope of the vibration velocity change curve at the same particle of two adjacent blasts shows that the first blast produces significantly higher damage to the surrounding rock than that of the subsequent blasts, and the 


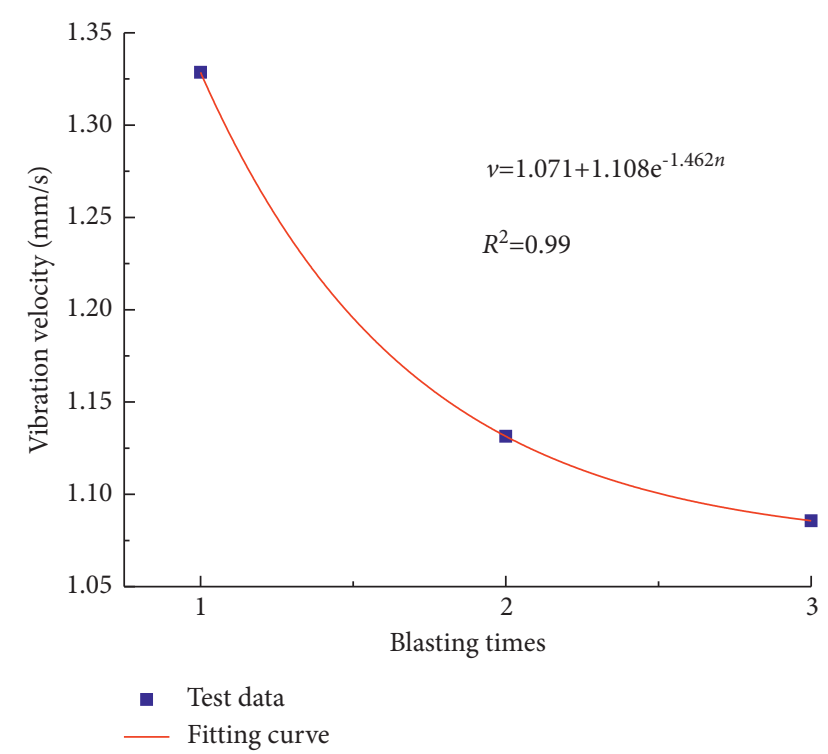

FIgURE 8: Relationship between blasting times and vibration velocity.

vibration velocity value from subsequent blasts is expected to gradually converge to a constant value. The attenuation of vibration velocity responds to the change of rock integrity; in practice, the difference of the subsequent blasting charge mass, charge structure, and the first blasting design can be adopted. The damage caused to the rock mass by shock wave from the first blast changes the propagation path of the shock wave from the next blast, which in turn achieves the purpose of controlling the particle vibration velocity.

The different damage of rock mass caused by blasting operation can be indirectly expressed by the particle vibration velocity. The greater the difference between the two vibration speeds, the greater the damage caused, while the smaller the difference between the two vibration speeds, the smaller the damage caused. The difference between the measured vibration velocity and the theoretical minimum vibration velocity can be used to reflect the attenuation characteristics of vibration velocity, expressed by

$$
\nabla v_{i}=v_{l i}-v_{s i}
$$

where $\nabla v_{i}$ is the difference between the theoretical value and the measured value of the $i$ th blast vibration velocity, $\mathrm{mm} / \mathrm{s}$, $v_{l i}$ denotes the theoretical value of the $i$ th blast vibration velocity, $\mathrm{mm} / \mathrm{s}$, and $v_{s i}$ denotes the measured value of the $i$ th blast vibration velocity, $\mathrm{mm} / \mathrm{s}$. As seen from Figure 9, the values of $\nabla v_{1}, \nabla v_{2}$, and $\nabla v_{3}$ are $1.54,1.74$, and $1.79 \mathrm{~mm} / \mathrm{s}$ for the three cycles of blasting counted, respectively. The value of $\nabla v_{i}$ becomes larger as the number of blasts increases, but the increasing trend becomes significantly slower, indicating that the damage inside the surrounding rock tends to stabilize as the number of blasts increases [24].

Under the premise of the constant distance between the explosion sources and particle, the vibration velocity of the same particle varies with the increase of blasting times. To analyze the difference between the number of different blasts and vibration speed, the normalized dimensionless vibration

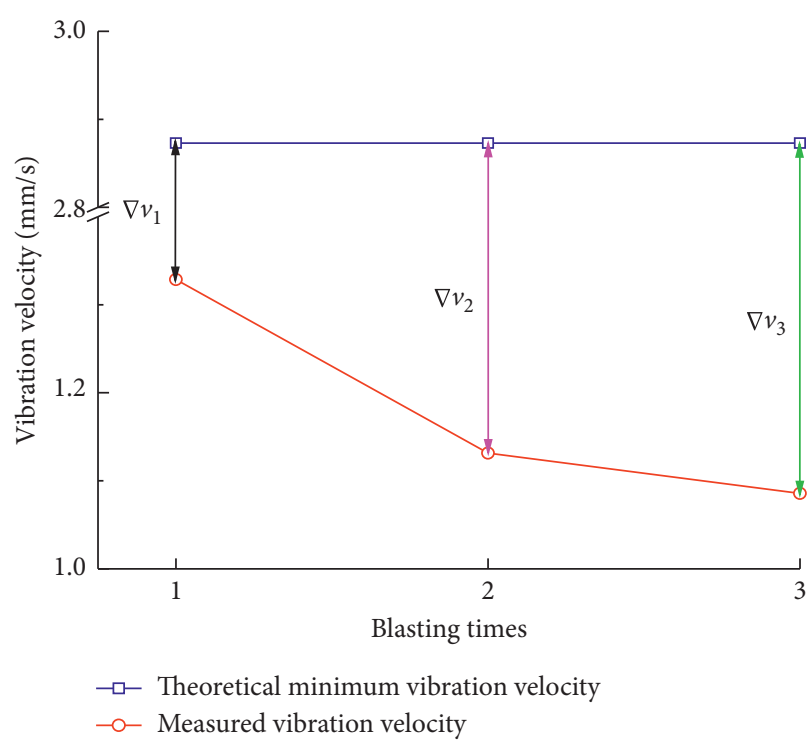

FIGURE 9: The difference between measured and theoretical values.

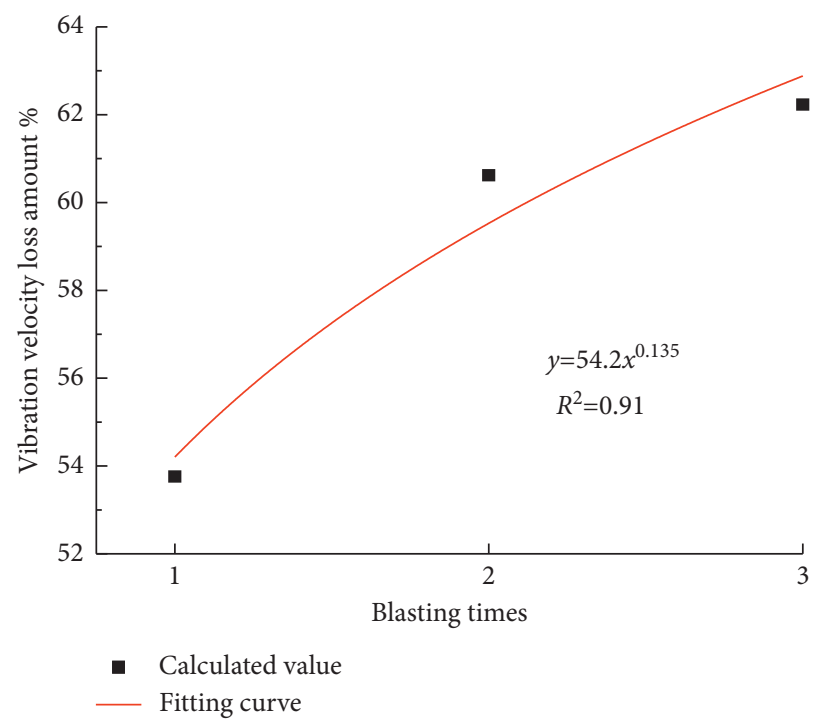

FIGURE 10: Relationship between dimensionless vibration velocity and blasting times.

velocity calculation of the particle vibration velocity under different blasting times is expressed by

$$
\nabla k_{i}=\frac{v_{l i}-v_{s i}}{v_{l i}},
$$

where $\nabla k_{i}$ is the dimensionless vibration velocity loss.

As seen in Figure 10, the dimensionless vibration speed in the first blasting is the smallest, and the dimensionless vibration speed of the particle gradually increases with the increase of the number of blasting cycles. The trend of the curve can be expressed by the power function $y=54.2 x^{0.135}$, and the specific amount of the loss of dimensionless vibration velocity in three consecutive cyclic blasts is $53.76 \%$, $60.62 \%$, and $62.23 \%$, respectively. The growth trend of the correlation curve becomes slower, indicating that the 
sensitivity of the particle vibration velocity to the blasting behavior decreases with the increase of the number of blasts.

\section{Conclusions}

The concealment of the shock wave propagation generated by blasting in fractured rock determines the complexity and high difficulty of its study. To reduce the effect of blasting vibration on the surrounding structures during the tunnel drilling-blasting excavation, by using the fine blasting design of the tunnel construction, the theoretical and measured values of particle vibration velocity were analyzed. The main results of the study are as follows:

(1) Based on the geological environment, combining with the selected equipment, the appropriate diameter and depth of the borehole are determined. The borehole depth and time-consuming per unit length and borehole velocity are not a linear relationship, and the time-consuming per unit length changes slowly first and then increases rapidly with the increase of the borehole depth. There is an obvious threshold, which can be expressed by the piecewise linear function.

(2) Through the fine blasting design, the negative phase superposition effect of segmented delay blasting shock wave waveform is realized, and reducing energy propagation and particle vibration velocity is achieved. The measured vibration velocities of the same particle in three cycles of blasting are 1.33, 1.13, and $1.09 \mathrm{~mm} / \mathrm{s}$, which are $46.24 \%, 39.39 \%$, and $37.79 \%$ of the theoretical minimum vibration velocity, respectively. The rationality of the fine blasting design is verified.

(3) The same particle for multiple blast vibration velocity test shows that the attenuation of vibration velocity is a negative exponential function with the increase of blasting times. The dimensionless vibration velocity loss increases as a power function with the increase of blasting times. The larger the loss is, the more the energy is lost in the process of shock wave propagation, which is conducive to ensuring the stability of protected buildings.

The designed charge directly determines the size of the energy generated by blasting, the physical properties of rock mass between explosion source and particle, the development degree of cracks determine the amount of shock wave energy absorption. In the actual engineering, considering the influence of multiple factors coupling effect with fractured rock mass on shock wave attenuation, the design of construction plans to suit the local conditions to reduce the speed of particle vibration as much as possible should be given great attention, making the blasting construction to environmental protection [25].

\section{Data Availability}

Relevant research data can be obtained upon request from the corresponding author.

\section{Conflicts of Interest}

The authors declare that they have no conflicts of interest.

\section{Acknowledgments}

This work was supported by the National Natural Science Foundation of China (51774C112) and the Fundamental Research Funds for the Universities of Henan Province (NSFRF200202).

\section{References}

[1] Y. Zhang, M. D. Wei, G. S. Su, Y. Li, J. B. Zeng, and X. Q. Deng, "A novel intelligent method for predicting the penetration rate of the tunnel boring machine in rocks," Mathematical Problems in Engineering, vol. 2020, Article ID 3268694, 15 pages, 2020.

[2] M. Koopialipoor, A. Fahimifar, E. N. Ghaleini, M. Momenzadeh, and D. J. Armaghani, "Development of a new hybrid ANN for solving a geotechnical problem related to tunnel boring machine performance," Engineering with Computers, vol. 36, no. 1, pp. 345-357, 2020.

[3] G. M. Foderà, A. Voza, G. Barovero, F. Tinti, and D. Boldini, "Factors influencing overbreak volumes in drill-and-blast tunnel excavation. A statistical analysis applied to the case study of the Brenner Base Tunnel-BBT," Tunnelling and Underground Space Technology, vol. 105, Article ID 103475, 2020.

[4] C. Yu, H. Z. Yue, H. B. Li, C. B. Zhou, S. C. Chen, and Z. S. Shao, "Analysis of blasting control parameters and reliability based on rock mass quality," Rock and Soil Mechanics, vol. 42 , no. 8, pp. 1-11, 2021.

[5] J.-G. Kim and J.-J. Song, "Abrasive water jet cutting methods for reducing blast-induced ground vibration in tunnel excavation," International Journal of Rock Mechanics and Mining Sciences, vol. 75, pp. 147-158, 2015.

[6] X. Y. Liu, M. Gong, H. J. Wu, and D. An, "Calculation and practice of blasting parameters of electronic detonator in tunnel under the influence of multi-factor coupling," Journal of Vibration and Shock, vol. 40, no. 5, pp. 24-32, 2021.

[7] J. Yang, X.-G. Yang, J.-W. Zhou, Y. Liu, B.-S. Dong, and H.-B. Li, "Comparative study of the excavation damage and $r$ of the deeply buried $\mathrm{j}$ II diversion tunnels using a TBM and the drilling-blasting method," Advances in Civil Engineering, vol. 2020, no. 2, pp. 1-14, 2020.

[8] C. D. Ma, W. B. Xie, Z. L. Liu, Q. Y. Li, J. Q. Xu, and G. S. Tan, "A new technology for smooth blasting without detonating cord for rock tunnel excavation," Applied Sciences, vol. 10, no. 19 , p. 6794, 2020.

[9] X. W. Chai, S. S. Shi, Y. F. Yan, J. G. Li, and L. Zhang, "Key blasting parameters for deep-hole excavation in an underground tunnel of phosphorite mine," Advances in Civil Engineering, vol. 2019, Article ID 4924382, 9 pages, 2019.

[10] B. Duan, W. Gong, G. Ta, X. Yang, and X. Zhang, "Influence of small, clear distance cross-tunnel blasting excavation on existing tunnel below," Advances in Civil Engineering, vol. 2019, no. 3, pp. 1-16, 2019.

[11] S. R. Wang, J. Y. Zhang, J. T. Li, F. L. Kong, and J. Q. Fan, "Analysis of vibration attenuation and energy consumption of blasting demolition chimney: a case study," Tehnički Vjesnik, vol. 27, no. 3, pp. 826-834, 2020.

[12] J. H. Yang, Q. H. Jiang, Q. B. Zhang, and J. Zhao, "Dynamic stress adjustment and rock damage during blasting excavation 
in a deep-buried circular tunnel," Tunnelling and Underground Space Technology, vol. 71, pp. 591-604, 2018.

[13] M. Chen, W. B. Lu, P. Yan, and Y. G. Hu, "Blasting excavation induced damage of surrounding rock masses in deep-buried tunnels," Ksce Journal of Civil Engineering, vol. 20, no. 2, pp. 933-942, 2016.

[14] Y. Fan, J. W. Zheng, X. Z. Cui, Z. D. Leng, F. Wang, and C. C. Lv, "Damage zones induced by in situ stress unloading during excavation of diversion tunnels for the Jinping II hydropower project," Bulletin of Engineering Geology and the Environment, vol. 8, pp. 1-27, 2021.

[15] L. T. Xie, P. Yan, W. B. Lu, M. Chen, and G. H. Wang, "Comparison of seismic effects during deep tunnel excavation with different methods," Earthquake Engineering and Engineering Vibration, vol. 17, no. 3, pp. 208-224, 2018.

[16] Y. Xia, N. Jiang, C. Zhou, and X. Luo, "Safety assessment of upper water pipeline under the blasting vibration induced by Subway tunnel excavation," Engineering Failure Analysis, vol. 104, pp. 626-642, 2019.

[17] N. Jiang, T. Gao, C. Zhou, and X. Luo, "Effect of excavation blasting vibration on adjacent buried gas pipeline in a metro tunnel," Tunnelling and Underground Space Technology, vol. 81, pp. 590-601, 2018.

[18] S. H. Chen, X. M. Liu, Z. H. Zhang, and C. M. Lin, "Analysis of surface vibration effect on tunnel excavation section induced by tunneling blasting," Chinese Journal of Geotechnical Engineering, vol. 42, no. 10, pp. 1800-1806, 2020.

[19] L. S. Shi, W. X. Gao, and L. T. Wang, "Experimental and numerical simulation study on blasting seismic effect of subway shallow buried tunnel," Transactions of Beijing Institute of Technology, vol. 38, no. 12, pp. 31-37, 2018.

[20] X. M. Liu and S. H. Chen, "Prediction of surface vibration waveform caused by cut hole blasting in tunneling," Chinese Journal of Geotechnical Engineering, vol. 41, no. 9, pp. 17311737, 2019.

[21] C. Zhu, M. C. He, M. Karakus, X. H. Zhang, and Z. Guo, “The collision experiment between rolling stones of different shapes and protective cushion in open-pit mines," Journal of Mountain Science, vol. 18, no. 5, pp. 1391-1403, 2021.

[22] D. Liu, W. B. Lu, M. Chen, and P. Yan, "Attenuation formula of the dominant frequency of blasting vibration during tunnel excavation," Chinese Journal of Rock Mechanics and Engineering, vol. 37, no. 9, pp. 2015-2026, 2018.

[23] F. Wu, R. B. Gao, J. Liu, and C. B. Li, "New fractional variableorder creep model with short memory," Applied Mathematics and Computation, vol. 380, Article ID 125278, 2020.

[24] F. Wu, H. Zhang, Q. L. Zou, C. B. Li, J. Chen, and R. B. Gao, "Viscoelastic-plastic damage creep model for salt rock based on fractional derivative theory," Mechanics of Materials, vol. 150, Article ID 103600, 2020.

[25] C. Zhu, M. He, M. Karakus, X. Zhang, and Z. Tao, "Numerical simulations of the failure process of anaclinal slope physical model and control mechanism of negative Poisson's ratio cable," Bulletin of Engineering Geology and the Environment, vol. 80, no. 4, pp. 3365-3380, 2021. 